\title{
Seismic Risk Perception in Al-Marj, Libya: A Case Study after the 1963 Earthquake
}

\author{
Somaia S. Suwihli1,2, Thomas R. Paradise ${ }^{1}$ \\ ${ }^{1}$ Department of Geosciences, University of Arkansas, Fayetteville, USA \\ ${ }^{2}$ Department of Geography, University of Benghazi, Benghazi, Libya \\ Email: ssuwihli@uark.edu
}

How to cite this paper: Suwihli, S.S. and Paradise, T.R. (2020) Seismic Risk Perception in Al-Marj, Libya: A Case Study after the 1963 Earthquake. Open Journal of Earthquake Research, 9, 349-366. https://doi.org/10.4236/ojer.2020.94020

Received: July 1, 2020

Accepted: August 3, 2020

Published: August 6, 2020

Copyright (c) 2020 by author(s) and Scientific Research Publishing Inc. This work is licensed under the Creative Commons Attribution International License (CC BY 4.0).

http://creativecommons.org/licenses/by/4.0/ (c) (i) Open Access

\begin{abstract}
Individual beliefs, knowledge, and perception play a vital role in understanding and coping with the consequences of earthquakes. These perceptions then mold the broader perceptions of risk and danger held by communities, which ultimately create public policy. This survey study was designed and conducted to assess the perceptions of seismic hazard and risk of earthquake survivors and residents in Al-Marj, Libya-a city razed in a 1963 tremor. In 2019, 364 earthquake survivors and residents were surveyed for their knowledge and perception of earthquakes. Surveys were conducted in Arabic and included demographic and narrative questions in addition to Likert-scaled responses. A number of predictable, surprising, and valuable correlations were found. It was found that during earthquakes most respondents prayed to Allah, or did nothing, in comparison to escape, seeking shelter, or running for help. The majority believed their neighborhoods were unsafe while questions illiciting some aspect of quake recurrence caused a complete refusal to answer; they commented "I do not know" or "only God knows". Most respondents did not consider preparation to be important, but younger respondents were relatively more prepared. Surprisingly, highly educated respondents were less prepared, however, they also attributed earthquakes to tectonic slipping and not divine retaliation or retribution. However, less-educated respondents stated "I do not know", "Allah punishes", or "Allah tests the believers". Most participants considered themselves well-informed about earthquakes from popular media sources (internet, TV, magazines). These findings were vital in gaining an insight into hazard perception and high-risk behavior in a seismically active region like Libya. When natural hazard recurrence (i.e. earthquakes) are better understood, then the potential consequences of injury, damages, and deaths may be assessed, and an overall plan to produce sustainable disaster management strategies and decrease risk can be created and implemented.
\end{abstract}




\section{Keywords}

Libya, Al-Marj, Risk Perception, Preparation, Vulnerability, Earthquakes

\section{Introduction}

Because of its unpredictable nature injury, death, and damages from earthquake, human life and property are often more vulnerable to this natural disaster [1]. In fact, a natural hazard becomes a disaster when it causes deaths, injury, and material losses [2]. This new perspective confirms that disasters do not occur, but are caused [3]. It takes a long time to recover from a disaster and regain normalcy. In terms of the natural hazard response, two major approaches have been recognized and addressed [4]. First, the top-down approach focuses on improved hazard and disaster response (e.g. through public awareness and hazard training programs) and hazard planning and regulation (e.g. through land-use planning, and the design and implementation of building codes). Second, the bottom-up approach puts greater emphasis on the necessity to understand the social, political and economic processes that create societal vulnerability to hazard [5]. The bottom-up approach, or the community-based approach, was first coined by Andrew Maskrey [6] through his influential book, Disaster Mitigation: a community based approach. Across Turkey, citizens demanded action by their governments when contractors had not followed building codes and had used low-quality materials; these poor construction standards exacerbated the damage following the 1999 Izmit earthquake [4]. In the US south Florida, when it became clear that poor construction methods were responsible for much of the avoidable damage caused by Hurricane Andrew in 1992 [7] similar outrage developed. Maskrey objected to the top-down perspective that many people are living in vulnerable situations due to lack of knowledge or understanding about hazard exposure or due to immediate economic prospects. Living in an area susceptible to serious earthquake exposure, in poorly constructed structures, for instance, may well be perceived to pose less of a direct threat to well-being than everyday concerns such as having no way of earning a living and having little to eat [6]. People are unlikely to adapt or change their behavior or habits to reduce vulnerability to natural hazards if this increases their vulnerability to other major concerns. In these situations, the top-down approach seems to be less effective in reducing community vulnerability. Therefore, it is argued that the first step for reducing vulnerability should come from within the community. People should be aware of, and concerned about their own safety [4]. Research has repeatedly confirmed that people are most likely to take protective action if they believe that they are at risk [8] [9] [10] [11] [12].

Under the Roman occupation of North Africa, the 262AD and 365AD earthquakes razed the region of Cyrenaica in northeastern Libya. However, since 1900 the coastal zone of northeastern Libya near Al Jabal Al Akhdar continues to be a 
seismically active, although most earthquakes produced moderate magnitudes, generally $\geq 4.5$ (MI). A major event was recorded in Al-Marj where the city was destroyed by such an earthquake (5.6R) on 21 February, 1963 [13]. This study focuses on perceptions of earthquake recurrence, construction standard policies, and the level of preparedness of the survivors of Al-Marj tremor. Here the belief, attitudes, knowledge, perception, and actions of the individuals were considered to play a vital role in understanding and coping with the consequences of quake.

\section{Study Site}

The modern city of Al-Marj, $\left(30^{\circ} \mathrm{N}, 20^{\circ} \mathrm{W}\right)$ in northeastern Libya, at the western end of the Jebel al-Akhdar Mountain (Figure 1), is the ancient Greco-Roman Cyrenaican town of Barce established c.550 B.C. [14] in the eastern coastal province of Libya. It was a part of the Greco-Roman province of Crete and Cyrenaica. The area came to be known as Barqa during the Islamic period [15]. The present town grew around a Turkish fort built in 1842 (now restored). Cyrenaica was also the name of the administrative division from 1927 during the Italian occupation of Libya when the Italians developed the town as an administrative center, market nexus, and hill resort from 1913-1941 [16]. The name, Cyrenaica was used in the Kingdom of Libya until 1963 [15].

Al-Marj is situated on an alluvial plain which has provided fertile soil for agriculture for centuries, which lead to its early settlement during Greek times [17]. The flat plain is located at the top of the first escarpment of Al Jebel al-Akhdar, which runs longitudinally descending toward the sea to the north, rising 200 to 400 meters above sea level. Directly behind this plain is the terrace of the second escarpment rising 400 to 875 meters above sea level also facing north, running in parallel with the first escarpment. Sited on the plain between the first and second escarpment is the city of Al-Marj. These two escarpments trend to the northeast created a "grand staircase" lifted tectonically from the

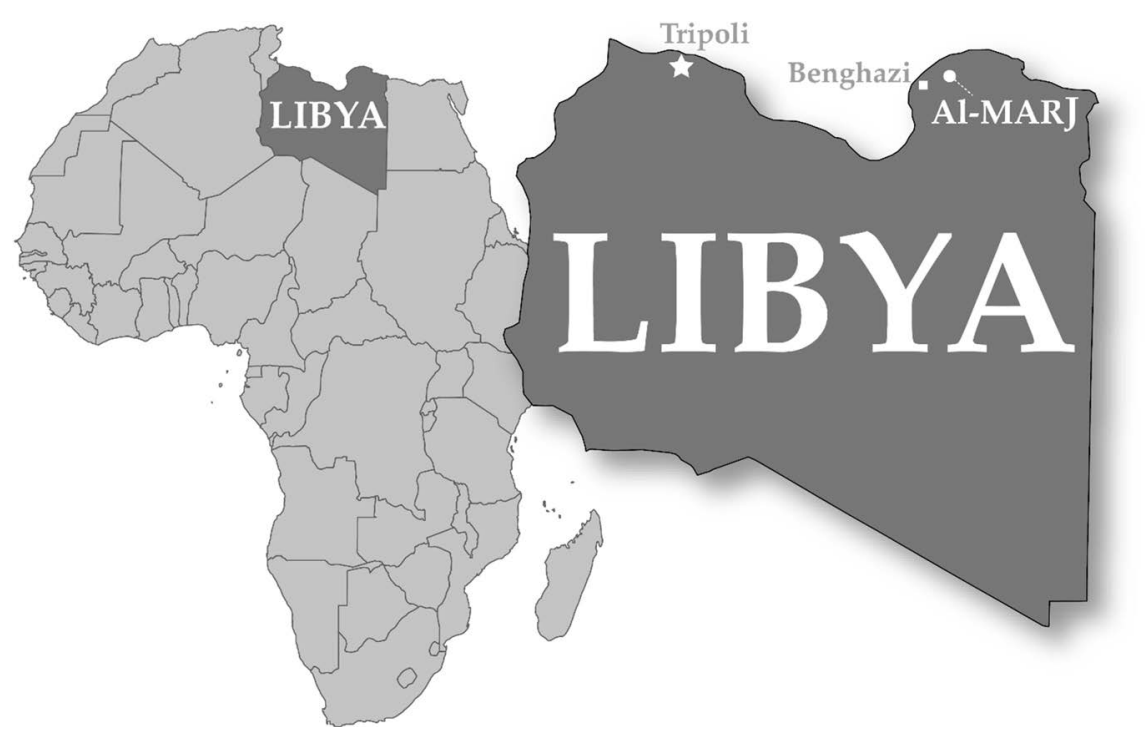

Figure 1. Location map of the study area. Cartography by authors, 2020. 
adjacent mountainous range of Al-Jebel al-Akhdar [18].

Al-Marj was destroyed in 1963, then rebuilt on rock substrates 3 miles $(5 \mathrm{~km})$ from the old city [18]. The new city is $90 \mathrm{~km}$ (56 miles) northeast of Benghazi and is the administrative seat of the Marj District. Al-Marj and Darnah are the major service and commercial centers and centers of major agricultural activities including fisheries [18]. It has been postulated that these escarpments are uplifted fault-plains, however recession has taken place since the scarps were formed, and the these controlling faults now exist north of the present-day escarpments [17]. Erosion has deteriorated the fault-bound cliffs leaving a rounded and cracked escarpment face and plain [18]. Figure 2 illustrates the coast of northeastern Libya in Al-Jabal Al-Akhdar areas which continues to be a seismically active.

\section{The 1963 Earthquake}

On 21 February 1963, at 17:14 (local time), during the $27^{\text {th }}$ night of Ramadan, an earthquake shook the region when the Muslim inhabitants of the town gathered in their houses to take their evening meal after the sundown. The shock was centered $13 \mathrm{~km}$ northwest of Al-Marj. The epicenter was located at $32.6^{\circ} \mathrm{N}$ and $20.9^{\circ} \mathrm{E}$, while the focus of the earthquake was approximately $33 \mathrm{~km}$ below the ground surface. The tremor hit with a Richter magnitude of 5.6, and a maximum intensity of IX on the modified Mercalli intensity scale [19]. The earthquake leveled most structures, killing 300 and injuring 375 people; the whole population of 13,000 residents was left homeless [17]. Five aftershocks followed the first shock with magnitudes greater than 4 which continued throughout the day [20] (Table 1).

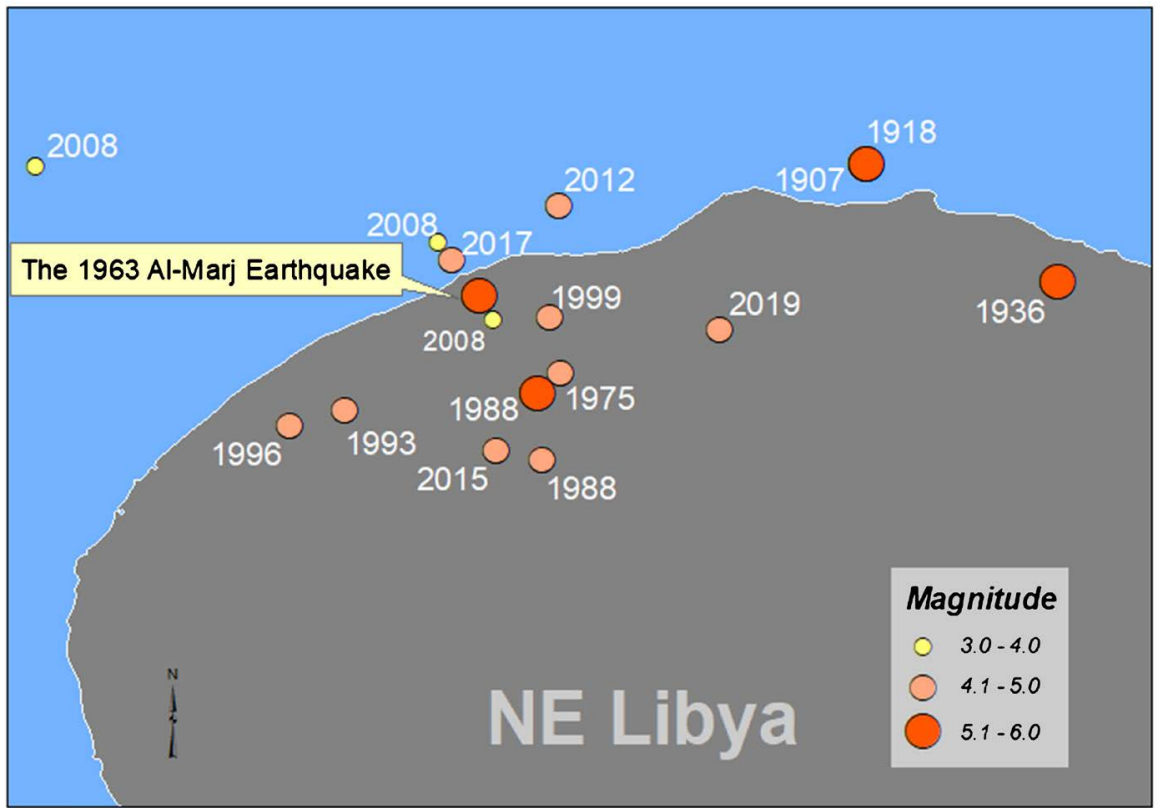

Figure 2. Distribution of the earthquakes that occurred in NE Libya (1900-2019). Data from USGS [13]. Cartography by authors, 2020. 
The next morning, two more quakes struck as rescue work was in full swing. The Libyan Air Force sent eleven air transports loaded with relief supplies from its base near Tripoli. American and British military forces, and Libyan soldiers and police provided food and tents to survivors while rescue workers dug through the ruins for others trapped, injured, or killed [22]. Libyan officials rushed from Tripoli to supervise rescue operations. An emergency was declared throughout the country by the Libyan government. After an appeal for help from local Libyan authorities, British troops were in charge of rescue operations. British assistance was flown from the Benghazi area and nearby Cyprus. A British-American control center was set-up in Al-Marj. In addition, U.S. planes sent medical personnel and relief supplies from the US' Wheelus AFB close to Tripoli, 300 miles west of the quake area. The first planes transferred a full field hospital with two surgeons, three other doctors, medics, and a medical group able to parachute into the earthquake area. British troops hurried to the scene with support from the station at Benghazi [23].

The poorly constructed stone and clay structures found in the city were responsible for injuries, human lives, and property (Figure 3). The structures Table 1. Basic data for the aftershocks.

\begin{tabular}{|c|c|c|c|c|c|}
\hline Date & $\begin{array}{l}\text { Origin } \\
\text { Time }\end{array}$ & $\begin{array}{c}\text { Location } \\
\text { Lat. }\left({ }^{\circ} \mathrm{N}\right) \text { Long. }\left({ }^{\circ} \mathrm{E}\right)\end{array}$ & $\begin{array}{c}\text { Depth } \\
(\mathrm{km})\end{array}$ & Magnitude & $\begin{array}{c}\text { Stations Reporting } \\
\text { P-Readings }\end{array}$ \\
\hline February 21 & $17: 24: 36$ & $32.6^{\circ} 21.1^{\circ}$ & 33 & 4.0 & 7 \\
\hline February 21 & $18: 33: 00$ & $32.9^{\circ} 21.0^{\circ}$ & 30 & 4.6 & 35 \\
\hline February 21 & $18: 36: 19$ & $32.6^{\circ} 21.0^{\circ}$ & 30 & 4.0 & 9 \\
\hline February 21 & $20: 26: 40$ & $32.6^{\circ} 21.0^{\circ}$ & 33 & $4.8-4.4$ & 70 \\
\hline February 22 & $02: 47: 15$ & $32.9^{\circ} 21.1^{\circ}$ & 33 & 4.3 & 23 \\
\hline
\end{tabular}

Sources: Gordon \& Engdahl [20] and Minami [19].

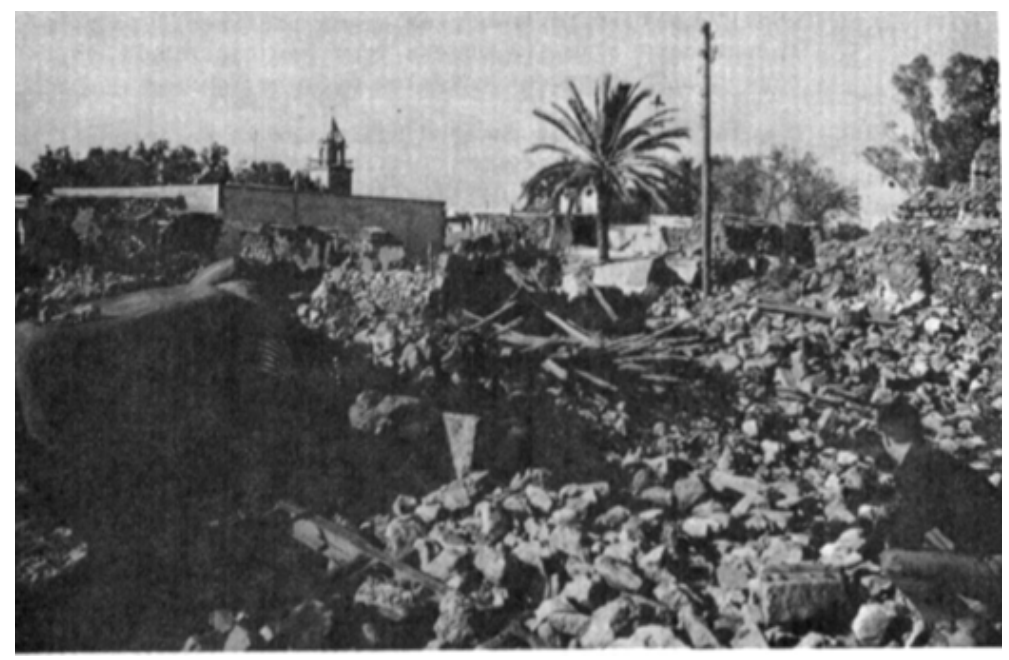

Figure 3. The heap of rubble stones in the popular housing area. In the center is the remainder of the fallen roof consisting of wooden rafters. Among the ruins, a building with girders and reinforced concrete columns remain standing though damaged [19]. 
comprised of rubble stone embedded in mud and/or clay suffered extensive damage (Figure 4). Also, construction that used sandstone or limestone mortared with lime, cement, or cement mortar but without reinforcement (e.g. steel bars) was susceptible to ground movement and presented a danger to residents in these buildings. Construction that implemented hollow concrete blocks for one-floor dwelling houses suffered moderate damage, although they were not reinforced. Buildings with reinforced concrete frames (foundations, columns girders, slabs) escaped serious structural damage, although their walls were badly cracked. It was only concrete structures with reinforced steel integration that survived the disaster, and they were uncommon. For example, the elevated water tank of reinforced concrete and the adjacent five-story storage silo near the railway station withstood the shock forces with no damage [19] (Figure 5).

\section{Perception, Risk, and Culture}

Perception is a process by which people interpret and organize their sensory impressions in order to give meaning to their environment... An individuals' behavior is based on their perception of what reality is not on reality itself [24]. Risk perception is the reaction of an individual or a social unit toward a natural disaster occurring, and this response is a result of their culturally-related perceptions formed from experiences, training, and/or education [25]. Humans perceive and act on risk in two essential ways. Risk as feelings refers to individuals' intuitive and instinctive reactions to danger. Risk as analysis brings logic, reason,

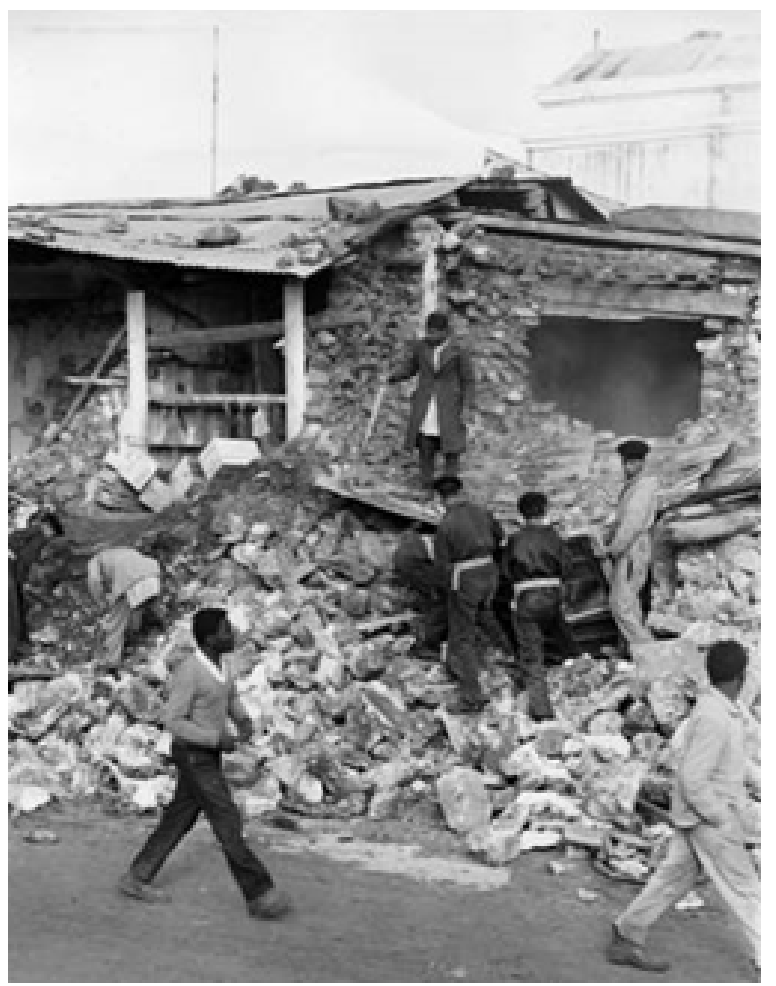

Figure 4. An example of damage to a rubble stone and mud house. Photo from Sulfium Forum [21]. 


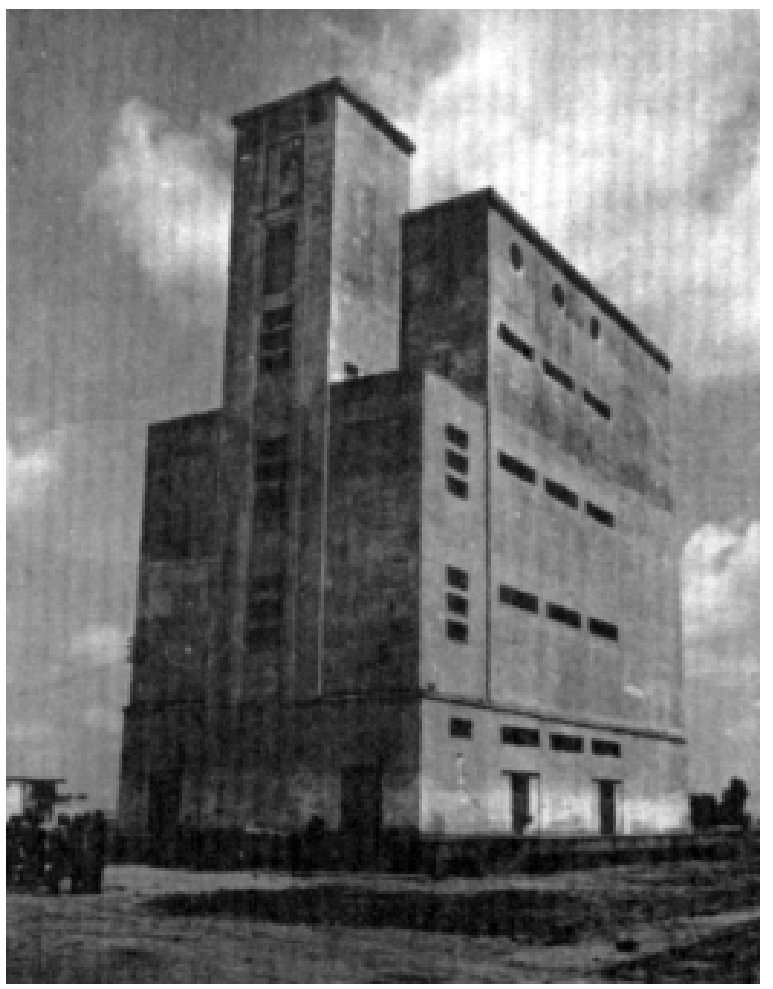

Figure 5. The five-story silo building of reinforced concrete construction. The structures with reinforced concrete walls withstood the earthquake forces [19].

and scientific consideration to bear on risk management [26]. Plato divided the mind into four realms-metaphysics, opinion, knowledge, and the sensationand suggested that perception existed within the opinion realm between the worlds of knowledge and sense. This idea that what we perceive emerges through a filter of sensing, understanding, realizing and utilizing was established 2500 years ago, and it is still widely accepted. The mind $s$ eye and filtering between observing and understanding has been in discussion for years, however, it started with the work of analysts such as Freud, Jung, and the Gestalt group that the modern notions of perceptions of danger, risk and safety began to be established. Freud in 1916-1917 designed a "mental topography" to characterize the complicated interaction of the psyche and reality as part of the "perception-consciousness system", trying to explain how people take in impressions and order them according to their relationships to impulse and instinct [27].

Freud [27] believed that the senses receive impressions, then organizing them according to their relationships to impulse and instinct, emphasizing that what we see is only the beginning; it will later be modified, classified and stored in realms that are immediately conscious. Jung [25] suggested that people first sense, classify, emplace and then judge on the basis of knowledge, experience, and context, and that added a new dimension to the concept.

Much of modern research in cognitive psychology operates with a model of man that is not passive but an active recorder, seeking and constructing an internal representation of the environment that will enable him to achieve his de- 
veloping needs, and to overcome and cope with the pervasive problem of adapting to the environment. As Bartlett [28] explained, man is involved in a continual "effort after meaning" [29]. The familiarity with repeated events has also been found to dramatically decrease the risk that is associated with some events, while some cultural appearances have been found to increase or decrease the risk relative perception. White [30] determined that floodplain inhabitants who have the greatest experience with the previous flooding underestimated the perceived risk of future floods. However, urban and rural flood-plain residents display differences in the perception of flood hazard. In prior studies of urban and agricultural landscapes, flood-plain residents indicated a greater sensitivity into floods terms of awareness for agricultural land users, while the frequency of hazard was the same for both agricultural land and urban users [31].

Attributing natural disasters to external forces beyond any human control has a great effect on how communities manage, modify, mitigate, cope and/or participate in decision-making. Lee [29] discussed that communities which accept some level of blame for natural hazard effects were more likely to be active in community decision-making and mitigation, which reduces risk. The realization that an individual's or community's influence can modify risk is a crucial method to effective mitigation and/or preparation for the next disaster [32] [33]. Different demographic factors are believed to have an effect on the positions and perceptions of individuals with regard to certain types of stressful events [34]. Gender connected to the knowledge of the causes of earthquakes, the ability to cope with severe risks, and emergency preparation [35] [36] [37]. Armaş [38] pointed out that the education level is closely associated with the extent to which people are aware of the seismic danger.

\section{Methodology}

The administration of survey instruments was used to assess the perceptions of seismic hazard and risk of survivors and residents of Al-Marj now 55 years after the devastating earthquake in 1963. It was designed and written in Arabic during Spring 2019 for targeting of university students, faculty, and staff, and in-home interviews for residents.

Stratified sampling techniques were applied to assess a representative sample of responses according to the respondent demographics. This kind of sampling (stratification) increases the reliability of estimates and is much utilized in opinion surveys [39]. For obtaining specific information and secure data appropriate for the analysis, the survey included a variety of indicators which included 37 questions divided into three sections: demographic information, earthquake historical knowledge, and seismic risk perception (Table 2). The Indicators included six demographic questions of sex, age, current address, years living in the place, education level, income, 14 questions designed to assess general quake historical knowledge such as "How many times have you felt an earthquake?; When did you last feel an earthquake?". Finally, 17 Likert-scale questions (1 - 5) 
were designed to elicit a general view of risk perception using a range of answers ( 1 = strongly disagree, disagree, no opinion, agree, 5 = strongly agree) (Figure 6) [40].

Using open-ended questions with discrete categories, the data allowed comparisons of subcategories or cross tabulation with other variable categories [41] which were used to analyze data in addition to descriptive statistics. Also, to answer some other questions, the respondents used Likert-scale techniques that correspond to a range of responses from strong agreement to strong disagreement [39]. These scaled responses allowed the researcher to quantify the answers that enabled inferential and descriptive statistical analysis. In the study, this technique proved simple and effective in correlating and explaining significant relationships.

The survey was administered during the Spring 2019 and continued for four months. The questionnaires were administered across Al-Marj and carried out at the University of Al-Marj and completed by the students of the university, the residents of the university community, and the surrounding area. The survey was conducted face-to-face, during class time for the university students, and in-home interviews for residents 20 - 70 years old. The two-member survey team consisted of two local lecturers of Geosciences and Engineering targeted earthquake survivors and their family members. A combination of Al-Marj residents

Table 2. Survey instrument sections.

\begin{tabular}{|c|c|c|}
\hline Sections & Example Questions & Obtained information \\
\hline Demographic information & $\begin{array}{l}\text {-What is your age and gender? } \\
\text {-What is your education attained level? } \\
\text {-What is your annual income? } \\
\text {-How many years have you lived in the area? }\end{array}$ & $\begin{array}{l}\text { The demographic information provides } \\
\text { indicators on the targeted social unit. }\end{array}$ \\
\hline Earthquake historical knowledge & $\begin{array}{l}\text {-How many times have you felt an earthquake? } \\
\text {-When do you believe was the last large earthquake? } \\
\text {-What did you do first during the last earthquake? }\end{array}$ & $\begin{array}{l}\text { Historical seismic information will clarify if } \\
\text { residents are aware of the seismic activity in } \\
\text { their region. }\end{array}$ \\
\hline Seismic risk perception & $\begin{array}{l}\text {-How much do you personally know about earthquakes? } \\
\text {-Where do you get your information about earthquakes? } \\
\text {-Do you prepare for another earthquake? } \\
\text {-Why do earthquakes happen? } \\
\text {-What did you first do when an earthquake happened? } \\
\text {-What part of the building is safer during an earthquake? }\end{array}$ & $\begin{array}{l}\text { Risk perception information provides how } \\
\text { the residents react with earthquakes and how } \\
\text { their response is related to their experiences, } \\
\text { training, and education. }\end{array}$ \\
\hline
\end{tabular}

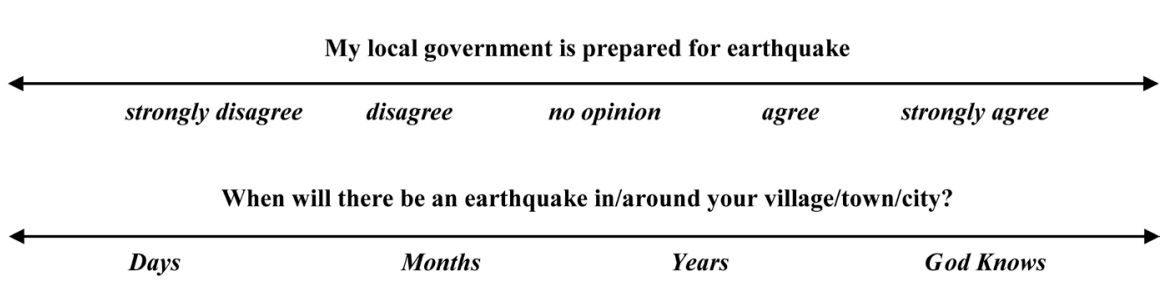

Figure 6. An example of the Likert-style question used in the survey. 
including 1963 earthquake survivors from various socio-economic strata were surveyed: University students, staff, and faculty, shopkeepers and customers, housewives, unemployed, and government officials.

More than 364 survey interviews were completed $(n=368), 27$ earthquake survivors were surveyed and interviewed and the remaining 337 were residents with memories from oral histories of the quake. Four incomplete surveys were rejected. Overall, the respondents of Al-Marj were friendly and more than willing to discuss the past earthquake and what may occur again. Additional notes, personal quotes, and anecdotes were written on many of the anonymous surveys by respondents often delighted to recount their experience, stories, and/or opinion of earthquakes. The survey data were then collected, compiled, and organized in spreadsheet formats and analyzed using Excel software.

\section{Results}

The aim of the study was to compare how respondents understood, perceived, and viewed seismic danger in Al-Marj using demographic, educational, economic, hazard, and vulnerability factors. Some of the results from the 364 successful surveys and interviews were predictable and some were revealing (Table 3). The

Table 3. Summary of descriptive statistics representing the overall responses to the demographic information and earthquake historical knowledge.

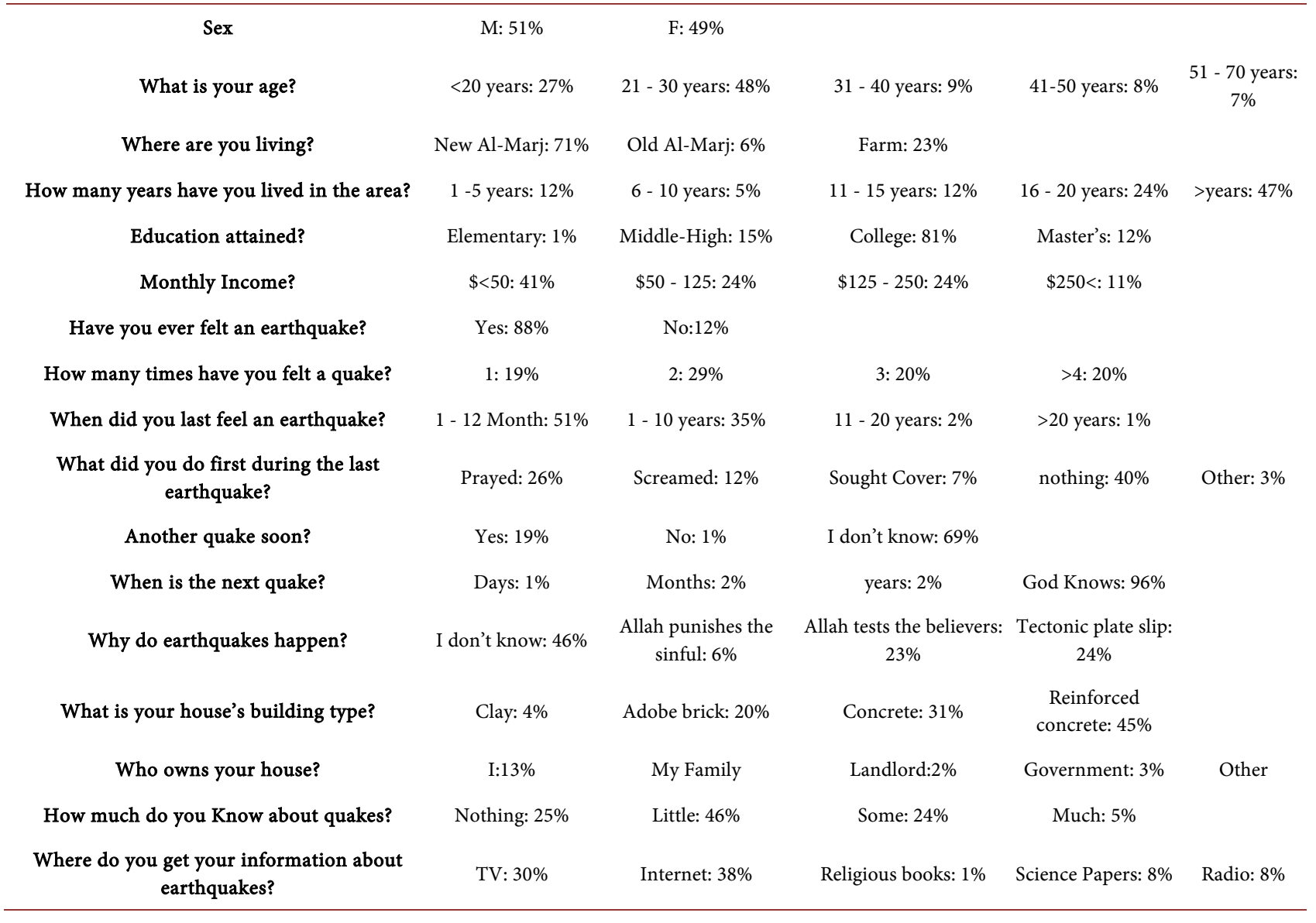


most notable results were found in the differences in perceptions between age, education, technology, and gender categories, in addition to the general lack of belief in the use of seismic predicting. This was revealed in the correlations between demographics and Likert-style responses. Especially interesting and statistically significant were the relationships of age and education level to the scaled responses.

Most respondents (88\%) felt earthquakes, some (12\%) have not felt one. Of those who experienced earthquakes; $51 \%$ stated that they were felt in the last 12 months, while 35\% in the last 1 - 10 years. 45\% did nothing during last earthquake, while $30 \%$ prayed, $13 \%$ screamed, and just $8 \%$ sought a cover (Figure 7 ). $78 \%$ did not want to predict whether if their city will have another earthquake, and they responded by "I do not know" and 22\% responded "yes"; $96 \%$ responded "God knows" for when the next earthquake will occur. Most participants refused to make a simple prediction even though they responded that their region was seismically active; moreover, their education level did not make any difference. In general, gender played a minor role in most of the correlations: $49 \%$ of the women and $42 \%$ of the men interviewed stated that they did not know the cause of earthquakes, $22 \%$ of the women and $22 \%$ of the men stated that Allah tests the believers. $22 \%$ of the women and $25 \%$ of the men stated earthquakes happen because of the slip of tectonic plates.

Relating to the relationship between education level and the cause of earthquakes, $46 \%$ said "I don't know", but higher-educated respondents tended to attribute earthquakes to the slip of tectonic plates alongside each other, and less-educated respondents tended to attribute earthquakes to divine testing and punishment (Figure 8).

Interestingly, for most of the participants, the Internet and TV were the primary source information regarding earthquakes. Nevertheless, age played a major role in choosing the source of this information: 15 - 30 years old depended more on the Internet and TV came second, while 31 - 50 years old depended

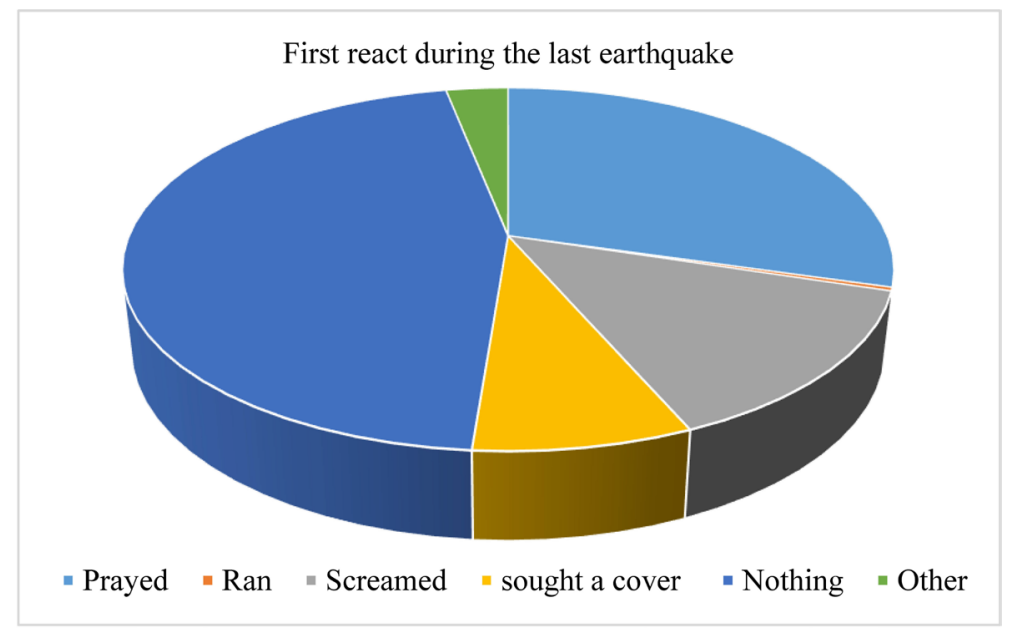

Figure 7. Most respondents did nothing while others chose to pray as first reaction when they felt earthquake. Only $8 \%$ sought cover. 
more on TV followed by the Internet. 51-70 years-old stated that TV had the highest percentage (52\%) followed by radio (30\%) (Figure 9). Although $59 \%$ of the respondents considered earthquakes represent a serious threat to their community, $49 \%$ were frightened from earthquakes; some (40\%) believed that their house is resistant to earthquakes. There was a correlation between the opinions on structural safety and building type. Of those who strongly agreed that their house was safe from earthquakes, $41 \%$ their houses were built from reinforced concrete, and 30\% from concrete. Of those who agreed, $57 \%$ lived in structures of reinforced concrete, and $25 \%$ in concrete (Figure 10).

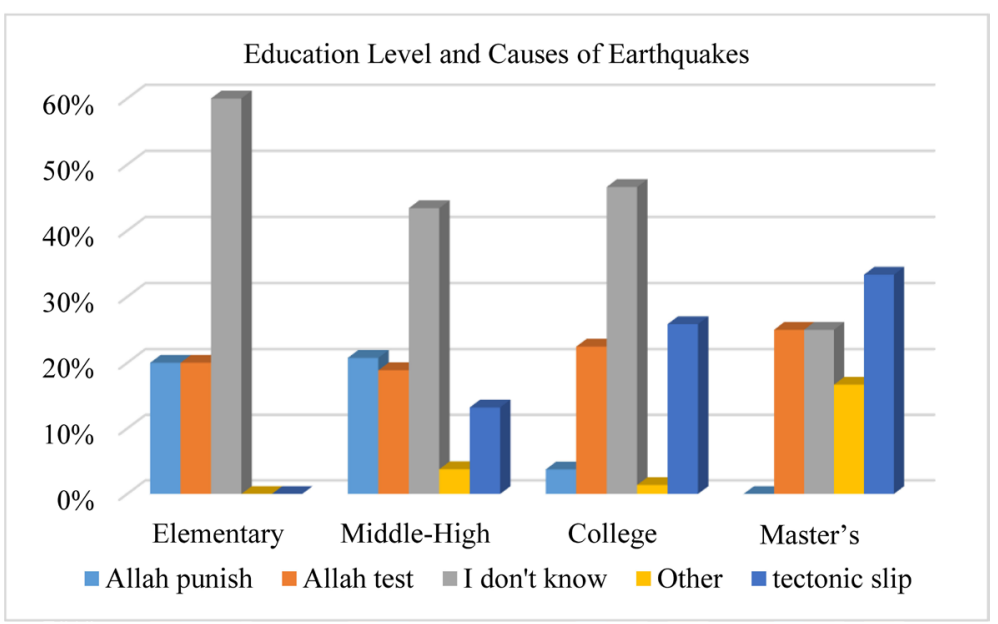

Figure 8. The relationship between education level and the cause of the earthquakes showed, 46\% said "I don't know, less-educated respondents tended to attribute earthquakes to divine testing and punishment, but higher-educated respondents tended to attribute earthquakes to the slip of tectonic plates alongside each other.

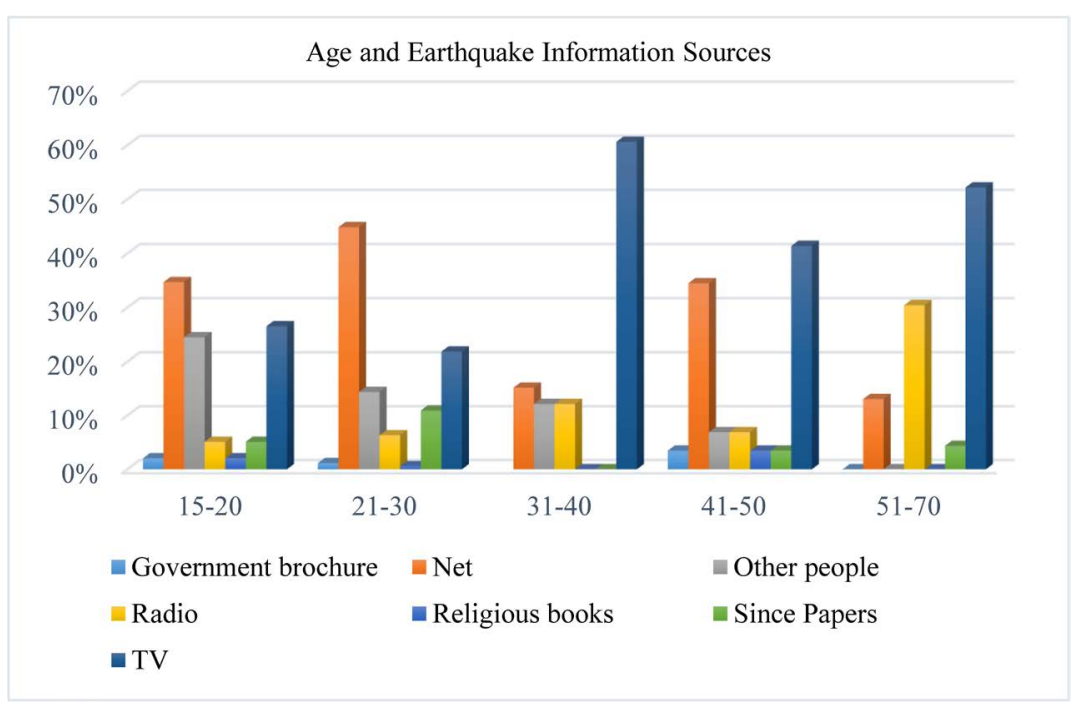

Figure 9. Earthquake information sources were varied between age categories. The categories 15 - 20 years old and 21 - 30 years old relied more on the Internet and TV came second, the categories 31 - 40 years old and 41 - 50 years old depended more on TV followed by the Internet, with the category 51 - 70 years old TV had the highest percentage followed by radio. 
As regard to earthquake preparedness, this question included five options: strongly disagree, disagree, no opinion, agree, strongly agree. 25\% respondents had no opinion. It was found that $53 \%$ of the respondents agreed that they were not at all prepared for earthquakes, while $22 \%$ were prepared. Concerning the relationship between age and earthquake preparedness, it was found that most of the respondents were not prepared, but younger respondents were relatively more prepared than older respondents (Figure 11). Higher-educated respondents were found to be less prepared than lower educated. About how their house was safe to earthquake forces and earthquake preparedness, it was found that of those who strongly disagreed or disagreed, their houses were believed to be resistant to earthquake forces. $75 \%$ did not prepare for another earthquake, and $25 \%$ did prepare. In terms of the responsibility to actively engage in earthquake preparedness, $44 \%$ respondents believed that citizens had a responsibility

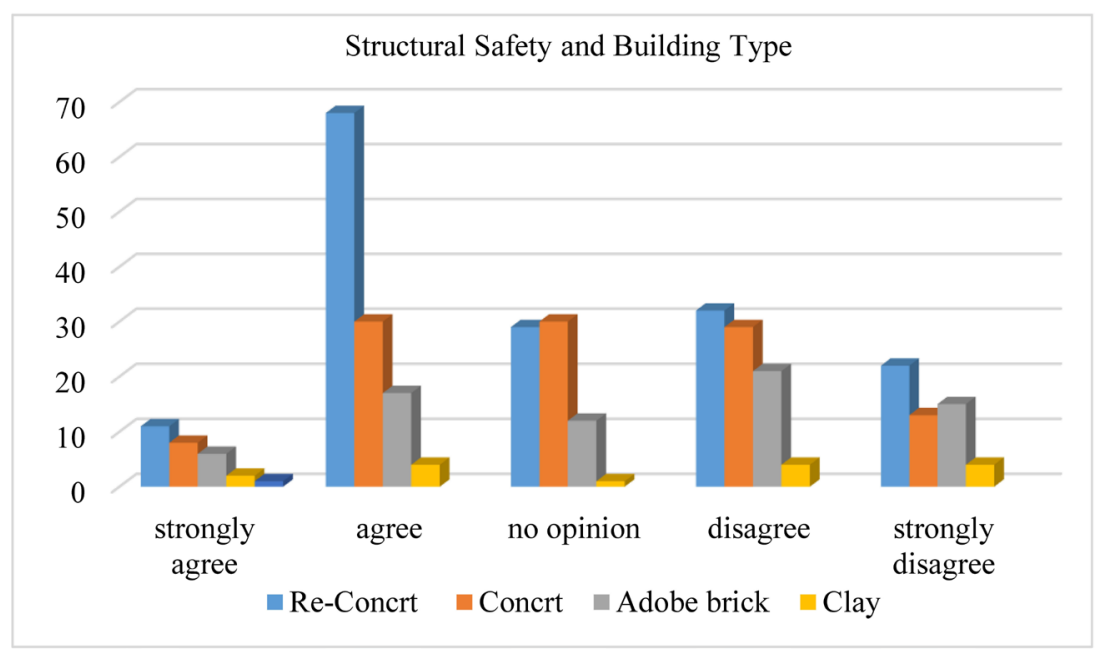

Figure 10. The correlation between the opinions on structural safety and building type showed that participants agreed that constructing houses with reinforced iron, cement mortar, and concrete will keep their house safe and reduce the damage.

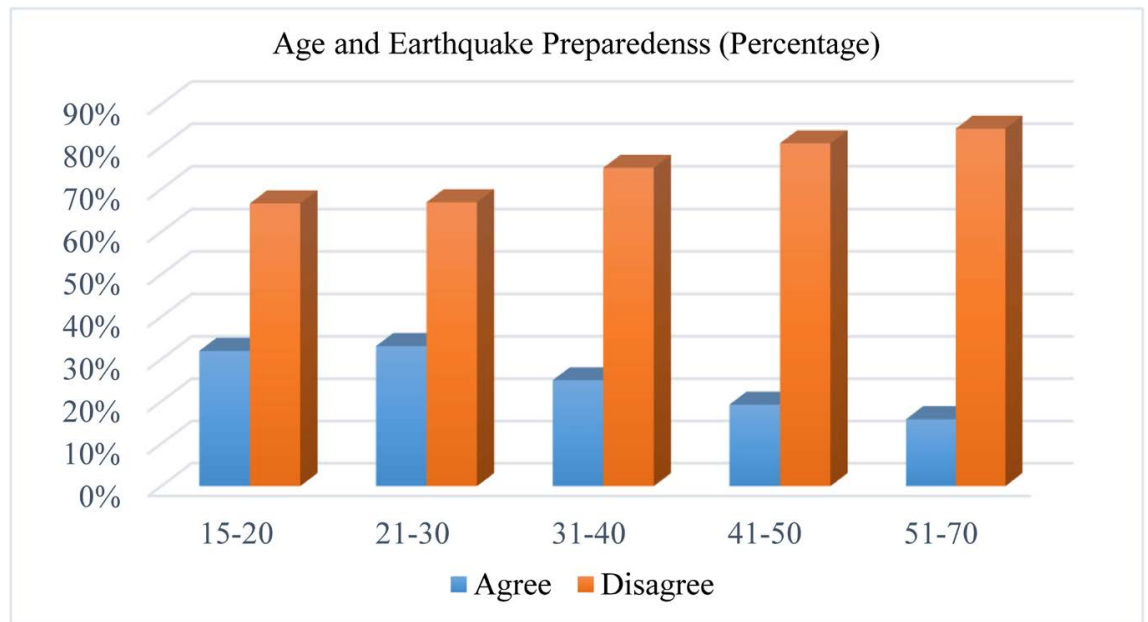

Figure 11. Younger participants are observed to be relatively more prepared than older participants. 
to actively engage in earthquake preparedness, and $57 \%$ of them think preparedness to reduce earthquake damages was not just the government's duty. However, 33\% respondents believed citizens did not have a responsibility in earthquake preparedness, and $43 \%$ of them saw this was just government's duty.

With regards to seismic risk and technology, four measures were found to have high priorities to the respondents: 1) choosing a site for residential development which was less vulnerable to earthquake will definitely minimize the risk related to earthquake (71\% lived in New Al-Marj, and 77\% indicated that Old Al-Marj was more dangerous to live); 2) constructing houses with steel rod reinforcement, cement, and concrete will reduce the damage ( $31 \%$ concrete and $45 \%$ re-concrete); 3) educating people will have an important role in reducing the earthquake damages; and 4) engaging in earthquake preparedness was the responsibility of the residents (44\%) beside the government's duty. This indicates that the respondents positively believed that taking preventive or preparatory measures will lead to decreased consequences. Ignoring risk altogether was attributed to two responses in the survey: (1): "Will there be an earthquake in your city" was answered "I do not know" (69\%) and/or 96\% of the respondents stated that "God knows" when the next earthquake will.

\section{Discussion and Conclusions}

An individual's or community's response to hazards is related both to the perception of the phenomena and to awareness of the opportunities to make adjustments. Rarely are people unaware of the existence of potential hazards in their environment, but their perception and cause may vary markedly from the estimates of professionals and experts [42]. In terms of overall risk perception, it has been observed and researched that people hold various perceptions about earthquakes. In this study, it was found that the individuals believed that an earthquake was a serious threat to their city; however, they knew nothing or little about earthquakes (71\%). So, they were ill-equipped with the necessary information about earthquake causes, safety, and damage prevention. They only understood the basics observable information about the tremors they had experienced. However, they were not informed about the causes, influences, or the significance of seismic activity and its consequences. Almost all the participants in this survey had accessed information about earthquakes from various popular media sources $(91 \%)$, and never from a scientific or more fact-based resource. During the Al-Marj Earthquake overwhelmingly they only prayed, screamed or "did nothing" (78\%). In his study of the floodplain communities of Bangladesh, Haque [43] found similar responses; the respondents prayed to Allah as their first solution to everyday, and catastrophic suffering, and to those imminent hazards. For the causes attributed to earthquakes most responded "I do not know, Allah punishes, or Allah tests the believers" (75\%), but some with higher education tended to attribute earthquakes to the slip of tectonic plates alongside each other. Thus, it goes against the findings of Demirkaya [44] in Turkey, who stu- 
died the perceptions of survivors of 1971 Burdur Earthquake in Yazlköy and Yarıköy. Most of his responses believed supernatural powers were the reason for earthquakes beyond or different than the omnipotence of Allah-God.

In addition, Libyan participants were frightened of recent earthquakes, and their neighborhood was believed to be unsafe from earthquakes (60\%). Although, younger respondents were relatively more prepared than older respondents, most of them were not prepared for future earthquakes (78\%), indicating a widespread apathy among the participants. This reluctance can be referred to the lower level of risk perception. In their memorable past, Al-Marj city experienced a deadly earthquake in 1963 [19], and although the respondents responded that their region was seismically active, they did not consider any form of preparation to be important. It was also observed that such a negative relationship between risk perception and preparedness was supported by prior research by $\mathrm{Pa}$ radise [45], and Azim and Islam [1]. Lower levels of risk perception may be due to two main reasons. First, it may be related to a lack of knowledge and/or shared information about previous earthquakes in Libya. Second, their view of earthquakes as events sent from Allah as acts of retribution for weak followers may also be widespread.

Researchers at the European Centre for Cultural Heritage (1993) have identified a possible correlation between earthquake frequency and building practices; in cases where events are infrequent, a "seismic culture of repairs" may develop where people are responsive to disaster reduction information in the immediate aftermath of an event, but then tend to revert back to pre-disaster poorer building techniques and unprepared lifestyles [46].

It was found that most of the survey respondents refrained from answering the questions related to risk perception and refused to make simple predictions. A high percentage (69\%) of them did not want to predict whether their city will experience another earthquake. Instead, they commented "I do not know" or "God knows". These common replies were shared equally by men and women, young and old, educated and uneducated, rich and poor. In his study of Agadir, Morocco, Paradise [40], and Azim and Islam [1] in their study in Jeddah, Saudi Arabia they found similar responses. So, from these findings in Al-Marj, the major influence of Islam to perception and behavior is understood.

However, an understanding and appreciation for better seismic monitoring indicates that the respondents strongly believed that taking preventive measures regarding seismic risk will lead to lower risks and decreased consequences. Even though it was found that the respondents did not take precautions against possible damage related to future tremors, the participants thought that the damage from earthquakes can be minimized by taking precautions and preparing. They explained that choosing a site for residential development which was less vulnerable to ground-shaking would definitely minimize the risk related to earthquake. Also, constructing houses with reinforced iron, cement mortar, and concrete will reduce the damage. 
It was also found that educating people may be an underestimated and under-utilized role in reducing related damages while earthquake preparedness may be as much as a citizen's responsibility and duty as that of the government. This indicates that individuals do believe that taking preventive or preparatory measures will lead to lower seismic risk and consequences. Since cultural values tend to change slowly, education may play a vital role in instilling modern values and attitudes that will ultimately lower risk and decrease injury, death, and damages.

It has been said that progress requires the need to address different types of vulnerability. Zaman [47] highlighted five vulnerability types: physical, social, economic, educational, and environmental vulnerabilityc. A community's effective mitigation against seismic risk necessitates consideration of all these factors. As such, interdisciplinary research and action become the fundamental prerequisite in the reduction of these vulnerabilities necessitating geologists, architects, politicians, engineers, community leaders, social scientists, and public policy makers to work together to produce sustainable disaster management strategies in a seismically active region like northeast Libya. When natural hazards in Libya like earthquake recurrence are better understood, then the potential consequences of injury, damages, and deaths may be assessed, and an overall plan to decrease risk can be created and implemented.

\section{Conflicts of Interest}

The authors declare no conflicts of interest regarding the publication of this paper.

\section{References}

[1] Azim, M.T. and Islam, M.M. (2016) Earthquake Preparedness of Households in Jeddah, Saudi Arabia: A Perceptual Study. Environmental Hazards, 15, 189-208. https://doi.org/10.1080/17477891.2016.1173006

[2] Montz, B., Tobin, G. and Hagelman, R. (2017) Natural Hazards: Explanation and Integration. Guilford Publications, New York.

[3] Oliver-smith, A. (1999) Peru's Five-Hundred-Year Earthquake: Vulnerability in Historical Context. In: Oliver-Smith, A., Hoffman, S.M. and Hoffman, S., Eds., The Angry Earth: Disaster in Anthropological Perspective, Psychology Press, Hove, 74-88.

[4] Degg, J. and Homan, M. (2005) Earthquake Vulnerability in the Middle East. Geography, 90, 54-66.

[5] Pelling, M. (2003) Paradigms of Risk. In: Pelling, M., Ed., Natural Disaster and Development in a Globalizing World, Routledge, Abingdon-on-Thames», 19-32. https://doi.org/10.4324/9780203402375

[6] Maskrey, A. (1989) Disaster Mitigation: A Community Based Approach.

[7] Wisner, B. and Luce, H.R. (1993) Disaster Vulnerability: Scale, Power and Daily Life. GeoJournal, 30, 127-140. https://doi.org/10.1007/BF00808129

[8] Fitzpatrick, C. and Mileti, D. (1991) Motivating Public Evacuation. International Journal of Mass Emergencies and Disasters, 9, 137-152.

[9] Gladwin, C., Gladwin, H. and Peacock, W.G. (2001) Modeling Hurricane Evacua- 
tion Decisions with Ethnographic Methods. International Journal of Mass Emergencies and Disasters, 19, 117-143.

[10] Tierney, K., Perry, R. and Lindell, M. (2001) Facing the Unexpected: Disaster Preparedness and Response in the United States. Joseph Henry Press, Washington DC.

[11] Zhang, Y., Prater, C.S. and Lindell, M.K. (2004) Risk Area Accuracy and Evacuation from Hurricane Bret. Natural Hazards Review, 5, 115-120. https://doi.org/10.1061/(ASCE)1527-6988(2004)5:3(115)

[12] Lindell, M. and Perry, R. (2004) Communicating Environmental Risk in Multiethnic Communities. Sage Publications, Thousand Oaks.

[13] United States Geological Survey (USGS) (2018) ANSS Comprehensive Earthquake Catalog (ComCat) Documentation. U.S. Geological Survey.

[14] Goodchild, R.G. (1968) Graeco-Roman Cyrenaica, Geology and Archaeology of Narthern Cyrenaica, Libya. Geogr. Archaeol. North Cyyrenaica, Libya, 23-40.

[15] Huesken, T. (2012) Tribal Political Culture and the Revolution in the Cyrenaica of Libya. Orient, German Journal for Politics, Economics and Culture of the Middle East, 1, 26-31.

[16] Luebering, J. (2014) Al-Marj. The Editors of Encyclopaedia Britannica. Encyclopædia Britannica, Inc., Chicago. https://www.britannica.com/place/al-Marj

[17] Campbell, A.S. (1968) The Barce (Al Marj) Earthquake of 1963. In: Barr, F.T., Ed., Geology and Archaeology of Northern Cyrenaica, Libya, Petroleum Exploration Society, Libya, 183-195.

[18] Urban Planning Agency (UPA) (2008) Third Generation Planning Project Benghazi Region 3GPP 2000-2025. Benghazi.

[19] Minami, J.K. (1965) Relocation and Reconstruction of Thr Town of Barce, Cyrenaica, Libya, Damaged by Earthquake of 21 February 1963. Third World Conference on Earthquake Engineering, 96-110.

[20] Gordon, D.W. and Engdahl, E.R. (1963) An Instrumental Study of the Libyan Earthquake of February 21, 1963. Earthquake Notes, 34, 50-56. https://doi.org/10.1785/gssrl.34.3-4.50

[21] Sulfium Forum (2010) Pictures of Rescue Operations for the Prairie Earthquake Victims in 1963. (In Arabic)

[22] Grandy, R. (1963) Quake Levels Libyan City in Seconds. The Daily Telegram, 23 Feb. 1963, 1.

[23] Earthquake in Libya Leave Hundreds Dead and Injured. Fergus Falls Daily Journal, 22 Feb. 1963, 1.

[24] Robbins, S.P. and Judge, T.A. (2013) Organizational Behavior. 15th Edition.

[25] Jung, C.G. (1959) The Writings of Carl Jung. Modern Library, New York.

[26] Slovic, P. and Peters, E. (2006) Risk Perception and Affect. Current Directions in Psychological Science, 15, 322-325. https://doi.org/10.1111/j.1467-8721.2006.00461.x

[27] Freud, S. (1963) Introductory Lectures on Psycho-Analysis. London.

[28] Bartlett, F.F.C. (1932) Remembering: An Experimental and Social Study. Cambridge University, Cambridge.

[29] Lee, T.R. (1981) The Public's Perception of Risk and the Question of Irrationality. Proceedings of the Royal Society of London, 376, 5-16. https://doi.org/10.1098/rspa.1981.0072

[30] White, G.F. (1945) Human Adjustment to Floods. University of Chicago, Chicago. 
[31] Burton, I. and Kates, R.W. (1964) The Perception of Natural Hazards in Resource Management. Natural Resources Research, 3, 412-441. https://doi.org/10.3366/ajicl.2011.0005

[32] Slovic, P., et al. (1977) Preference for Insuring against Probable Small Losses: Insurance Implications. The Journal of Risk and Insurance, 44, 237-258. https://doi.org/10.2307/252136

[33] Slovic, P. and Weber, E.U. (2002) Perception of Risk Posed by Extreme Events. In: Risk Management Strategies in an Uncertain World, Palisades Publishing, New York, 1-21. https://doi.org/10.1017/CBO9781107415324.004

[34] Soffer, Y., et al. (2011) The Relationship between Demographic/Educational Parameters and Perceptions, Knowledge and Earthquake Mitigation in Israel. Disasters, 35, 36-44. https://doi.org/10.1111/j.1467-7717.2010.01191.x

[35] Taylor, S. (2005) Gender Differences in Attitudes among Those at Risk for Huntington's Disease. Genetic Testing, 9, 152-157. https://doi.org/10.1089/gte.2005.9.152

[36] Eisenman, D.P., et al. (2006) Differences in Individual-Level Terrorism Preparedness in Los Angeles County. American Journal of Preventive Medicine, 30, 1-6. https://doi.org/10.1016/j.amepre.2005.09.001

[37] Paradise, T.R. (2008) Islam and Earthquakes: Seismic Risk Perception in a Muslim City. Journal of Islamic Law and Culture, 10, 216-233. https://doi.org/10.1080/15288170802285447

[38] Armaş, I. (2006) Earthquake Risk Perception in Bucharest, Romania. Risk Analysis, 26, 1223-1234. https://doi.org/10.1111/j.1539-6924.2006.00810.x

[39] Kothari, C. (2004) Research Methodology: Methods and Techniques. New Age International, New Delhi.

[40] Paradise, T.R. (2005) Perception of Earthquake Risk in Agadir, Morocco: A Case Study from a Muslim Community. Environmental Hazards, 6, 167-180. https://doi.org/10.1016/j.hazards.2006.06.002

[41] Haring, L.L., Lounsbury, J.F. and Frazier, J.W. (1992) Introduction to Scientific Geographic Research. Wm. C. Brown Publishers, Dubuque.

[42] Burton, I., Kates, R. and White, G. (1993) The Environment as Hazard. Second Edition, Guilford Press, New York.

[43] Haque, C.E. (1987) Non-Bengali Refugees in Bangladesh: Patterns, Policies and Consequences. In: Rogge, J.R., Ed., Refugees: A Third World Dilemma, Rowman \& Littlefield, Totowa, 217-226.

[44] Demirkaya, H. (2008) The Effects of the Yazıköy-Epicentre Burdur Earthquake (12 May 1971) on the Residents of the Village. Journal of Beliefs \& Values, 29, 243-252. https://doi.org/10.1080/13617670802465763

[45] Paradise, T.R. (2006) Perception of Seismic Risk in a Muslim City. The Journal of North African Studies, 11, 243-262. https://doi.org/10.1080/13629380600802961

[46] Homan, J. (2004) Seismic Cultures: Myth or Reality. Second International Conference on Post-Disaster Reconstruction: Planning for Reconstruction, 22-23.

[47] Zaman, Q. (1999) Vulnerability, Disaster and Survival in Bangladesh: Three Case Studies. In: Oliver-Smith, A. and Hoffman, S., Eds., The Angry Earth: Disaster in Anthropological Perspective, Routledge, Abingdon-on-Thames», 192-212. 